\title{
Filaggrin and atopic march
}

Ivana Čepelak', Slavica Dodig*1, Ivan Pavić2

'Department of Medical Biochemistry and Hematology, Faculty of Pharmacy and Biochemistry, University of Zagreb, Zagreb, Croatia ${ }^{2}$ Department of Pulmonology, Allergology and Immunology, Children's Hospital Zagreb, Zagreb; School of Medicine University of Zagreb, Croatia

*Corresponding author: slavica.dodig@zg.t-com.hr

\begin{abstract}
There is an increasing number of experimental, genetic and clinical evidence of atopic dermatitis expression as a pre-condition for later development of other atopic diseases such as asthma, food allergy and allergic rhinitis.

Atopic dermatitis is a heterogeneous, recurrent childhood disease, also present in the adult age. It is increasingly attributed to systemic features and is characterized by immunological and skin barrier integrity and function dysregulation. To maintain the protective function of the skin barrier, in particular the maintenance of $\mathrm{pH}$, hydration and antimicrobial functions, the filaggrin, among others, plays a significant role. Filaggrin is a multifunctional, histidine-rich, insoluble protein. The lack of filaggrin is associated with various cutaneous (e.g. ichthyosis vulgaris, allergic contact dermatitis) and non-cutaneous (e.g. diabetes, inflammatory conditions of the gastrointestinal tract) diseases and may be a result of genetic, immunological factors combined with environmental factors.

In this review we summarised (emphasized) recent findings in understanding the role of filaggrin in atopic dermatitis and other diseases, participants in the atopic march.
\end{abstract}

Keywords: atopic dermatitis; atopic diseases; filaggrin

\section{Introduction}

The term atopy, which was first coined by Coca and Cooke in 1923, represents immunoglobulin (Ig) E-mediated type I hypersensitivity reactions (1). Childhood atopic diseases typically develop in mucosal surfaces, such as skin, respiratory and gastrointestinal system, showing a high degree of comorbidity. Prevalence of atopic diseases, including atopic dermatitis (AD), asthma, allergic rhinitis $(A R)$, and food allergies (FA), has increased in recent decades and currently affects up to $20 \%$ of the population worldwide (2). These diseases seem to be closely related. The process by which several atopic diseases are interconnected throughout life, in this case "progression" of AD into asthma and AR is an epidemiological phe- nomenon commonly referred to as "atopic march" (3). The term refers to "time progression" from AD to asthma and AR during childhood, suggesting that $A D$ is an "entry point" for subsequent atopic diseases (4-6) (Figure 1). However, there are opinions that $A D$ is not a causal factor for the atopic march, and that the sequence of events does not always have to be the same (7). Belgrave et al. in addition to some other researchers, question the paradigm of the atopic march, considering it's too simplified and needs to be revised $(8,9)$. They explain it by the fact that most of the studies involving atopic march have been conducted based on cross-sectional statistical analysis on the general population, not taking into account the heteroge- 


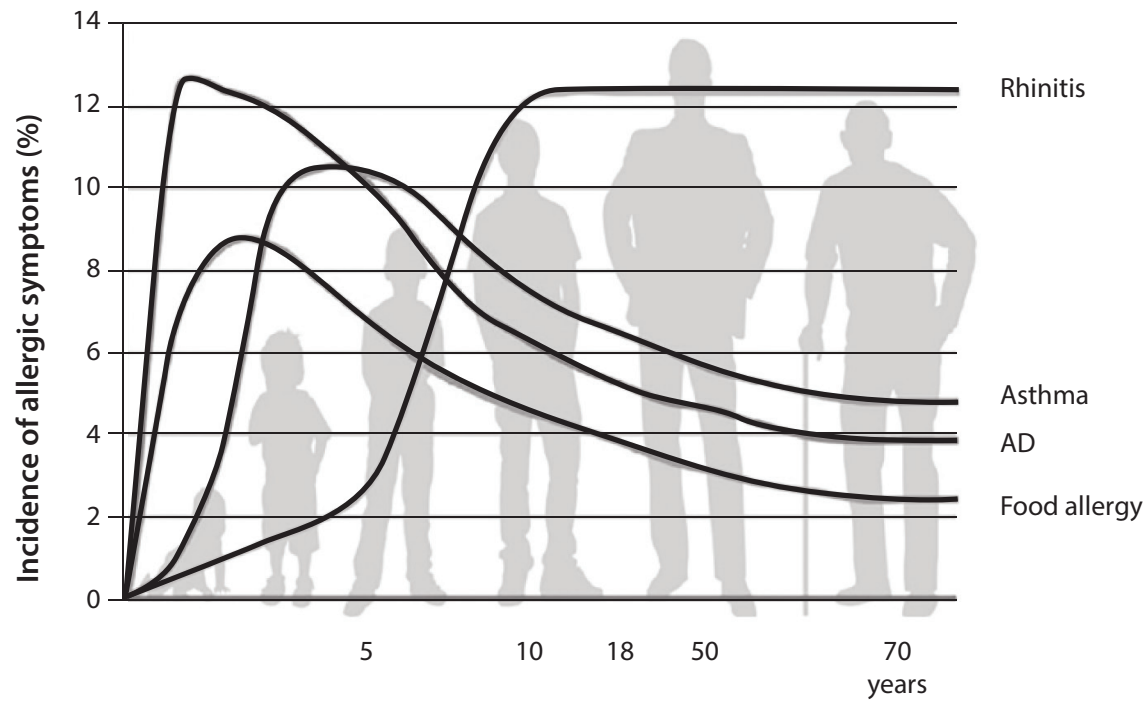

Figure 1. Atopic march. AD - atopic dermatitis. Modified according to (6).

neity of the chronology of the development of symptoms. They hypothesized that children with $A D$ that later develop asthma and AR may represent a specific phenotype. Although mentioned in the context of the atopic march, evidence of $A D$ related to FA is unclear and deficient (10). According to Hill et al. atopic diseases have some common multiple genetic and environmental predisposing factors, share immune characteristics of one or more allergen-specific Th2 responses, and include type 2 effectors phases in which specific $\lg \mathrm{E}$, granulocyte activation and other inherited factors occur (11). Most of the investigations of the causal nature of "progression" are aimed at seeking evidence that supports the premise that AD of early childhood encourages the development of FA and respiratory allergies via systemic sensitization resulting from impaired skin barrier function. Thus, the hypothesis that the main cause of atopic diseases is a defect in epithelial barrier integrity is accepted $(12,13)$. The most investigated causes of the epidermal skin barrier impairment in $A D$, as the initiator of atopic march, are a lack of filaggrin (FLG) associated with decrease of ceramide and significant activation of epidermal proteases (14).

In this review, we focus on the FLG molecule and its importance in maintaining normal skin barrier function and on current knowledge of the signifi- cance of FLG deficiency in diseases associated with atopic march. An overview of the recent knowledge of the nature of these conditions and their association with the role of FLG will be given. Appropriate scientific papers were selected on the PubMed using the following headings and keywords, and their combinations: filaggrin, profilaggrin, filaggrin mutations, atopic dermatitis, eczema, epidermal dysfunction, allergic rhinitis, food allergies and asthma. The search included epidemiological, genetic and clinical examinations, mainly on patients of various ages, regardless of the ethnic group.

\section{Atopic march development}

Causes of skin barrier dysfunction can be intrinsic and extrinsic. Of the intrinsic causes, apart from the mutation of the gene encoding FLG, mutations of numerous other genes, such as the SPINK5 gene encoding a serum protein (Kazal type 5), and CDSN genes encoding corneodesmosin were investigated $(15,16)$. Extrinsic causes are scratching environmental irritation, microbes, viruses, protein allergens, etc. The reactions that follow skin barrier impairment and precede Th2 inflammation and $\lg$ E synthesis include various cytokines (e.g. interleukine (IL)-25, IL-33 IL-4, IL-13, IL-5, etc.) and various 
cell types (e.g. basophilic and eosinophilic granulocytes, dendritic cells, mast cells and other types of cells). However, the TSLP (thymic stromal lymphopoietin), a type I cytokine produced by keratinocytes through the protease-activated receptor-2 (PAR-2) mediated nuclear factor kappa B (PAR-2/NF-kB) pathway, has the greatest significance. This cytokine has an essential role in the initiation of allergic inflammation in the skin. It activates Langerhans cells that promote differentiation of naive T-cells in Th2 cells in lymph nodes $(16,17)$. In addition, TSLP reduces the FLG expression in human skin, and acts as a sensory neuronal activator, resulting in itching $(18,19)$. Some authors consider that TSLP in the circulation can be a marker of lung responses to allergens. The TSLP could also be an important therapeutic target for reducing asthma and AR in children with AD (20).

Genetics play a greater role predisposing $A D$ to $A R$ and $A D$ to asthma than environmental factors (21). In addition, the relationship between $A D$ and asthma, and between asthma and AR, does not depend on common environmental factors of early life. Therefore, various genes were studied such as genes responsible for epidermal integrity (FLG, CLD, etc.), genes responsible for the functioning of the immune system (e.g. IL-13, IL-33, etc.), the nonspecific immune response participant genes (e.g. glutathione-S-transferase) and the genes responsible for chronic tissue inflammation (e.g., COL29A1 gene encoding collagen, ADAM33 gene expressed in fibroblasts and smooth muscle cells, etc.) $(5,10)$. Despite differing opinions on the paradigm of atopic march, it is currently accepted that the primary disorder is the disturbed structure of the stratum corneum (SC) or barrier function. Thereafter, an increased absorption of allergens (allergic sensitization) predisposes the patients to the development of other atopic diseases. Genetically or acquired loss of FLG with epidermal structure impairment results in significant changes in both skin hydration and increased skin $\mathrm{pH}$. Consequently, serine proteases activity is increased. Serine proteases via suitable mediators recruit and activate innate cell types that release IL-25, IL-33 cytokines, and particularly cytokine TSLP. The TSLP promotes the activation of dendritic cells, which migrate into the lymph organs and activate naive $T$ cells and $B$ cells, finally resulting in Th2 immune response. Increased penetration of allergens due to the disturbed structure of the skin barrier contributes to the Th2 immune response. The TSLP and the proinflammatory cytokines migrate to various pathways entering into systemic circulation and consequently in the airway and nasal mucosa resulting in asthma and AR. On the other hand, Th2-cytokines such as IL-4, IL-13, IL-25, as well as cytokines of other T-cell subtypes, whose number increases in $A D$ depending on the subtype of disease, may suppress FLG expression in keratinocytes or aggravate inborn barriers defect through positive loop feedback. The pattern of atopic march development, including FLG deficiency and currently known major factors, is illustrated in Figure 2.

\section{What is filaggrin?}

Filaggrin (from "FILament AGgregating pRotelN) is a structural, S100 calcium-binding epidermal SC protein (22). It binds the intermediate filament of keratin producing micro-fibrils and is responsible for the normal SC function. It is a product of the proteolytic activity of the serine protease group enzymes to a large (molecular mass $(\mathrm{Mm})>400$ $\mathrm{kDa})$, insoluble and functionally inactive precursor molecule - profilaggrin. Profilaggrin is a complex, highly phosphorylated molecule rich in histidine and is the main constituent of the F-type keratohyaline granules of the stratum granulosum (SG). The profilaggrin expression is under the control of transcription factors such as the Activator protein 1 (AP-1) transcription factor family members (23). Profilaggrin encodes the FLG gene, one of the genes that encode proteins with epidermis formation function. It is localized on the short arm of chromosome 1 and belongs to the group of socalled epidermal differentiation complex (EDC), located in region 1q21. During the epidermal differentiation process of keratinocytes in the boundary between SG and SC, the profilaggrin molecule is dephosphorylated under the influence of phosphatase and becomes more soluble (24). Further action of different proteases results in cleavage of the profilaggrin molecule in several stages, sepa- 


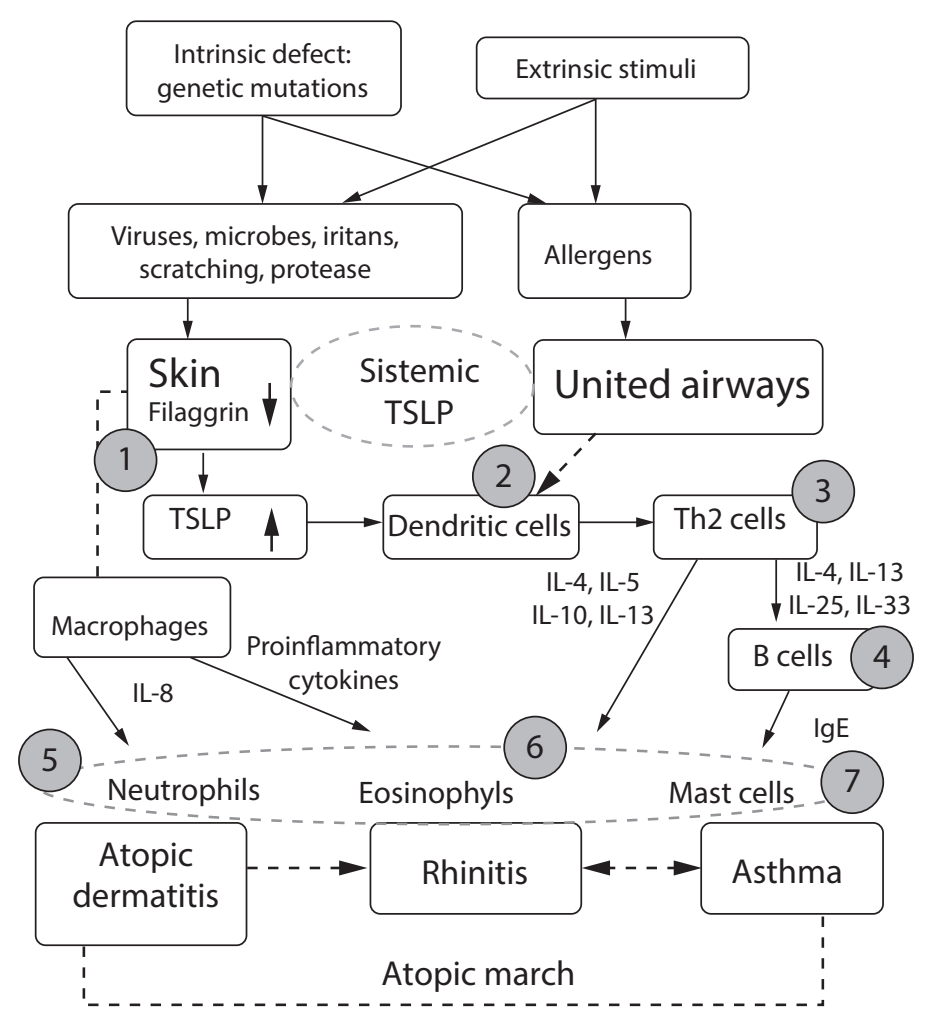

FiguRE 2. The mechanisms of atopic march. Inherited or acquired filaggrin deficiency results in immune and inflammatory changes. In addition, inflammatory and immune changes may result in filaggrin deficiency. Therefore, there is a positive feedback loop. Skin barrier impairment caused by deficiency of filaggrin; reduced filaggrin function leads to increased activity of TSLP, which through dendritic cells acts to promote both Th2 cell adaptive immune responses and Th2 innate immune cell response (marked as 1). Allergen uptake and presentation to dendritic cells in a Th2 context (marked as 2). Th2 cell expansion and activation (marked as 3). B cells activation and IgE switch (marked as 4). Neutrophil recruitment and activation (marked as 5). Eosinophil recruitment and mediators' release (marked as 6). Immunoglobulin E binding to the high-affinity IgE receptor (FcERI), on mast cell and basophil receptors (marked as 7). Th - T helper. IL - interleukine. IgE - immunoglobulin E. TSLP - thymic stromal lymphopoietin.

rating the $\mathrm{N}$ - and $\mathrm{C}$-terminal domains of the molecule, splitting the central part into trimers and dimers, and finally into 10-12 functional monomers the FLG molecules. Each FLG molecule consists of 324 amino acids, with an Mm of $37 \mathrm{kDa}$. The resulting FLG monomers aggregate keratinic filaments along with the catalytic activity of the transglutaminase-1 enzyme, resulting in the marked morphological and cytostructural changes of keratinocytes (become flattened corneocytes). In addition to FLG, many other proteins, such as loricrin, involucrin, small proline-rich proteins, are involved in the construction of the cornified envelope (25). In the further course of epidermal differentiation, separation of the part of FLG from the structure of the cornified envelope occurs resulting in post- translational conversion of arginine residues into the citrulline residues. The transformed FLG molecule is subject to the action of caspase-14 and is degraded. The FLG degradation products include a mixture of hygroscopic amino acids such as glutamine, histidine, alanine and their derivatives such as trans-urocanic acid (tUCA), degradable product of histidine and pyrrolidone carboxylic acid (PCA), degradable glutamine and glutamic acid product (26). These compounds along with some other such as hyaluronic acid, lactate, sodium, potassium, magnesium, phosphate, calcium, and citrate are the main constituents of so-called natural moisturizing factor (NMF) of the skin (27). The main characteristics of profilaggrin, FLG and its degradation products are presented in Table 1. 
TABLE 1. Main characteristics of profilaggrin, filaggrin, and its degradation products (amino acids)

\begin{tabular}{ccc}
\hline $\begin{array}{c}\text { Profilaggrin } \\
(\mathbf{M m}>\mathbf{4 0 0} \mathbf{~ k D a})\end{array}$ & $\begin{array}{c}\text { Filaggrin } \\
(\mathbf{M m} \approx \mathbf{3 7} \mathbf{~ k D a})\end{array}$ & $\begin{array}{c}\text { Amino acids } \\
\text { (NMF) }\end{array}$ \\
\hline $\begin{array}{c}\text { Main constituent of keratohyalin granules, } \\
\text { calcium-binding polyprotein, enucleation } \\
\text { during cornification, keratinocyte-calcium } \\
\text { signalling }\end{array}$ & $\begin{array}{c}\text { Contribution to SC structure and function, } \\
\text { aggregation of intermediate filaments, } \\
\text { inhibition of transepidermal water loss }\end{array}$ & $\begin{array}{c}\text { Epidermal hydration, acidification, } \\
\text { photo protection, immunomodulation, } \\
\text { antistaphyloccoccal effect }\end{array}$ \\
\hline
\end{tabular}

SC - stratum corneum. NMF - natural moisturizing factor. Mm - molecular mass. According to reference (27).

To date, approximately 60 loss-of-function FLG mutations have been identified, with a difference in the spectra of mutations between different populations (28). The frequency of FLG mutation in the general population is $8-10 \%$. The most common mutations in the European population are the R501X and 2282del4 mutations, resulting in premature transcription or inability to appropriately process profilaggrin in FLG. Mutations R244x and S3247X were found with significantly lower frequency (29). Lack of functional FLG due to the FLG gene mutation and to inflammatory and proinflammatory mediators that may affect FLG expression (acquired deficiency), results in a dysfunction of processes necessary for the corresponding protective SC role.

\section{Filaggrin and skin barrier}

The skin barrier function is largely dependent on SC. The interior of the corneocytes consists mainly of keratin filaments aggregated by FLG, which is one of components that provide a scaffold for the extracellular lipid matrix. Filaggrin degradation products maintain in part for the both, water-holding capacity and acidic pH of the SC (25). Natural moisturizing factor components are essential for skin barrier integrity, i.e. for skin hydration, skin $\mathrm{pH}$ modulation, immunosuppressive properties, antimicrobial defence, photosensitivity and skin elasticity (27). Because of water loss, there is the loss of skin elasticity. Inadequate humidity of the skin can also stimulate the production of proinflammatory mediators. The skin $\mathrm{pH}$, normally ranging from 4.5 to 5.5 , is increased. Endogenous causes of skin pH increase are amino acid deficiency, disruption of de- composition of amino acids into tUCA and PCA, degradation of fatty acid from epidermal phospholipids, and changes of $\mathrm{Na}^{+} / \mathrm{H}^{+}$transmembrane transport. Increased $\mathrm{pH}$ results in increased activity of serine proteases that can activate some cytokines and cause inflammatory reactions. The exogenous causes of $\mathrm{pH}$ increase include the microbial skin flora metabolites, the activity of sweat glands, and sebum derived compounds. Changing $\mathrm{pH}$ from neutral to alkaline values favours the development of various pathogens on the skin surface, most commonly Staphylococcus aureus and Candida albicans. All these changes result in reduced SC cohesion, enabling penetration of allergens and other pathogens in the skin.

Filaggrin mutations, i.e. FLG deficiency is also associated with various skin diseases (ichthyosis vulgaris, eczema herpeticum, atopic dermatitis, periodic infection with Staphylococcus aureus, allergy to nickel, allergic contact dermatitis in combination with $A D$, eczema, etc.) but also non-skin diseases (e.g. asthma in combination with $\mathrm{AD}$, peanut allergies, allergic rhinitis, diabetes) (30).

\section{Therapeutic approaches}

New therapeutic approaches directed to epidermal barrier defects are being attempted (31). Primary intervention in the treatment of diseases involving FLG deficiency is directed to improving profilaggrin processing into FLG, the recombinant FLG supplementation, as well as the NMF supplementation. It is believed that such a therapeutic approach could have a significant effect on a broader range of diseases associated with FLG gene mutation carriers, persons with FLG deficien- 
cy caused by inflammation, or in persons with genetic or inflammatory enzyme variants that allow the conversion of profilaggrin into FLG. Most of the studies of the effects of such a therapy have been made in both animal models, and in vitro tests; the results are promising. However, a beneficial effect on the development and progression of atopic march in human samples has yet to be established. For more reliable conclusions about the effectiveness of such therapy, longer periods of disease monitoring are required.

\section{Atopic dermatitis and filaggrin}

Atopic dermatitis is a common multifactorial skin disease of childhood, and it is postulated as the first manifestation of the atopic march (32). The prevalence of $A D$ has increased in recent decades and currently affects up to $20-30 \%$ of children and to $3 \%$ of adults worldwide (3). It has some common features with FA, asthma and AR including abnormality of skin barrier function, allergen sensitization and type 2 immune response (33). Clinical manifestations of $A D$ are the result of synergis- tic action of genetic and immune mechanisms in combination with environmental factors (climate, nutrition, obesity, etc.). The disease is characterized by inflammation, immune dysregulation, skin barrier dysfunction, and in most but not all (10$40 \%$ of $A D$ patients) with IgE-mediated sensitization to food and environmental allergens. Major symptoms include xerosis, eczema lesions, dry itchy skin, and chronic or relapsing dermatitis. Consequently, the continuous itchy-scratch cycle results in trans-epidermal water loss and secondary skin infections (34) (Figure 3).

The form of $A D$ with a normal serum IgE concentration is known as a non-atopic or intrinsic AD. It is not related to other atopic diseases, but the clinical picture does not differ from atopic or extrinsic AD (36). In addition to skin, systemic sensitization is also associated with AD. According to Brunner et al. various comorbidities are investigated, such as association with cardiovascular, neuropsychiatric, malignant diseases, but proof of this connection requires further longitudinal studies (37). Traditionally, the dysfunction of the adaptive immune system is considered a primary pathogenic mech-

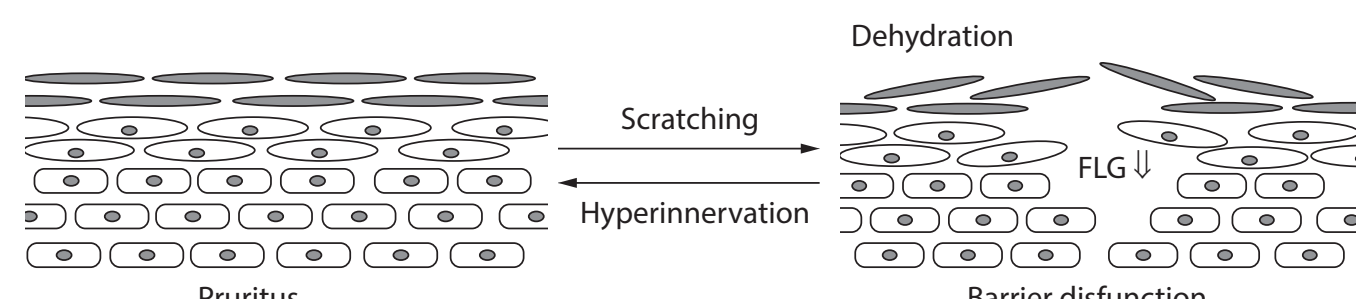

Pruritus

Barrier disfunction

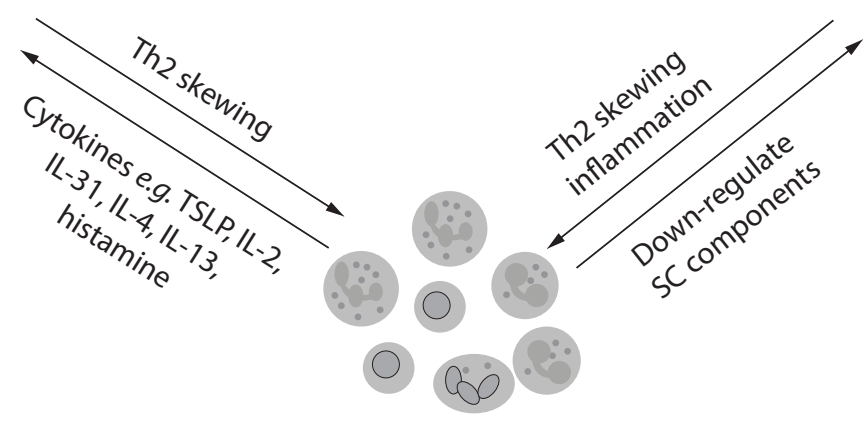

Immune responses

Figure 3. The relationship between itching, skin barrier abnormalities and immune dysregulation. Scratching due to itching may aggravate skin damage. Dry skin stimulates itching by increasing the density of epidermal nerve fibres. Scratching also promotes Th2 chemokines, eosinophil recruiting chemokines, and TSLP. Obviously, the immune response can induce itching through the secretion of numerous cytokines that can act as a pruritogens. FLG - filaggrin. TSLP - thymic stromal lymphopoietin. Th - T helper. IL - interleukine. SC - stratum corneum. Modified according to (35). 
anism that initiates AD. Specifically including Th2/ Th1 imbalance and inflammation, which secondary results in skin-structure barrier impairment, which is considered an epiphenomenon. In a number of studies that followed the discovery of FLG gene mutation, an epidermal barrier impairment including FLG deficiency was considered as a primary pathogenic initiation mechanism of AD (38).

According to Thyssen et al. the important observations that put FLG into the centre of pathogenesis of $A D$ are: impaired FLG values in skin with or without lesions in patients with $A D$, the fact that approximately $50 \%$ of patients with moderate or severe $A D$ have at least one FLG mutation, that a decrease in the number of copies of FLG increases the risk of $A D$, that the decreased values of FLG were demonstrated in skin lesions despite the absence of FLG mutations, and that some of the existing therapies can repair FLG values (39). The development of $A D$, along with genetic and immune mechanisms, is also strongly influenced by environmental factors such as industrialization, stress exposure, obesity, excessive use of antibiotics, sedentary lifestyle, etc (40).

Specifically, the damaged skin-barrier function allows penetration of various allergens/haptens, environmental pollutants, and toxins resulting from bacterial colonization on the one hand, and on the other hand by sensitization to allergens. For example, it has been shown that phthalate metabolites, common ingredients of cosmetic products, increase the risk of $A D$, and that children with FLG P478S mutations absorb phthalates (41). The pathogenesis of $A D$ is also linked to $F L G-2$ gene mutations that encode the filaggrin-2, a protein similar to FLG by localization, amino-acid composition and biochemical properties (42). Also, other genes may play a role in the pathogenesis of $A D$, e.g. HRNR gene encoding the hornerin, RPTN gene encoding the repetin, a SPINK5 gene encoding Kazal-type 5 serine protease, LOR gene encoding loricrin, and other genes by location close to epidermal differentiation complex (43-45). In addition, gene mutations that are involved in the immune response (e.g. IL-4, IL-5, IL-13, IL-18, IL-31, IL-4RA, a binding protein gene e.g. claudin (CLDN1) and desmoglein 1 protein (DSG1) have been investigated
$(46,47)$. In the focus of the investigation of pathogenesis of $A D$ and atopic march is also a study of various epigenetic modifications such as methylation of DNA, FLG, TSLP, and variants of enzymes involved in synthesis and profilaggrin processing (48). Most studies have shown that the lack of structural and functional epidermal molecules does not only disturb the structure of the barrier, but is also a mediator of immune and allergic processes. There is a reciprocal relationship between the skin barrier dysfunction and the immune response in pathogenesis of AD. Therefore, AD can still be considered as a disease of skin barrier impairment and immune disease (49). Mechanisms of $A D$ progression into other atopic diseases are not quite clear. One of the participants in this process is the platelet activating factor (PAF), an endogenous phospholipid inflammatory mediator released by various types of cells, e.g. alveolar macrophages in allergic and inflammatory conditions (50). Release of PAF is associated with increased vascular permeability, eosinophilic granulocyte attraction, and bronchoconstriction.

\section{Filaggrin, asthma, and allergic rhinitis}

Data on FLG expression in human digestive tract and unified respiratory system are contradictory and more often negative $(51,52)$. Moreover, mechanisms linking FLG variants with asthma, AR or FA are not entirely understandable. However, based on some animal models, it is considered that skin sensitization, including the Th17 cell subpopulation, facilitated by acquired FLG defects or mutations can indirectly result in local but also systemic inflammation in distant organs $(53,54)$.

\section{Asthma}

An estimated 300 million people worldwide suffer from asthma $(55,56)$. Asthma is caused by genetic predisposition and various external stimuli (e.g. airborne allergens), which result in partial or full reversible bronchoconstriction. It is often presented differently in children and adults; there are different phenotypes such as intermittent, persistent, aspirin sensitive and severe form. Symptoms mainly involve severe breathing, chest tightness, dyspnoea 
and cough, especially at night and in the morning (55). Asthma is the result of a disturbed interaction of the respiratory epithelium, the innate and adaptive immune system and the environmental factors. In this regard, a large number of genes, particularly genes responsible for the Th2 cytokine expression in Th2 cells (IL-4, IL-13, IL-5), other T-cell subtypes, dendritic cells, eosinophil and neutrophil granulocytes, mast cells, macrophages and IgE were investigated (57). In the pathogenesis of asthma, the role of ADAM33 protein, responsible for bronchial hyperresponsiveness, stimulation of smooth muscles of the airways, fibroblast proliferation and cytokine production has been studied (58). Moreover, the nitric oxide vasodilator system, various growth factors (e.g. transforming growth factor-beta, granulocyte-macrophage colony-stimulating factor), inflammatory lipid mediators such as leukotrienes and prostaglandin D2, TSLP which induces key changes in dendritic cells and other molecules were also investigated (59). Palmer and colleagues first described the relationship between the R501X and 2282del4 variants of FLG genes and asthma in persons with $A D(60)$. Case control, family and population studies and/or other FLG mutations, which then followed, more clearly indicate the meaning of a defective epidermal barrier in pathogenesis, primarily $A D$, and then other atopic disorders - AR and asthma $(61,62)$. Generally, the results of investigating the association of these conditions with groups of subjects of different geographic origin show that those patients with FLG mutation have a moderately higher risk of developing asthma than those without genetic mutation, regardless of AD status (63). The risk is significantly higher (3 to 6-fold) in patients with AD and in carriers of FLG mutation (64). It appears that the presence of a particular FLG mutation also has implications for some clinical features of asthma such as the severity of the disease, the number of acute exacerbations, the degree of airway obstruction, and the quantity of asthma control medications to control the disease (65).

\section{Allergic rhinitis}

Rhinitis is one of the most common chronic conditions in children, but also in adults. It is an inflam- mation of nasal mucosa, characterized by nasal congestion (rhinorrhoea), itching, sneezing, and nasal blockage. Causes of rhinitis may be allergies, infections, drugs, hormones, various irritants, and may also be of idiopathic origin (66). Allergic rhinitis is characterized by a Th2 immune response including mediators such as IL-4, IL-5, IL-13, whose activity results in the formation of $\lg E$ and recruitment of eosinophilic and basophilic granulocytes, mast cells, which further release different mediators, such as histamine and cysteinyl leukotriene, as a vasoactive substance (67). About $40 \%$ of AR patients had asthma, and up to $80 \%$ of asthmatic patients reported AR (68). These data are not surprising since, besides the anatomical connection, the inhaled air is heated, moistened, and filtered in the nose to maintain homeostasis of the respiratory system (69). In the literature, therefore, more work is devoted to the connection of AR and asthma. Of the mechanisms considered in this connection, it seems that the most acceptable one is the systemic inflammatory response, as cited by Chawes (70). The same author found a significant association of FLG mutations with AR, but not with non-allergic rhinitis. Other authors also report about such association $(71,72)$, which supports the hypothesis of the primary role of epidermal barrier impairment in this disease.

\section{Open questions}

Most of the scientific articles included in this review consider FLG deficiency, in particular caused by the FLG mutation, as one of the causes, the key risk factor, the $A D$ modifier, and consequently the possible causes of atopic march.

The disruption of the skin barrier function associated with the lack of FLG in AD is, along with other known pathogenic factors, the basis for the allergic sensitization to food allergens and aeroallergens, and the consequent development of asthma and AR. The key questions in this context are 1) how to predict $A D$ and when to prevent the occurrence of $A D ; 2)$ whether timely repair of skin barrier could prevent progression of $A D$ and thus the possible development of asthma and AR; and 3) what an appropriate therapeutic strategy should 
include? To get the correct answers to these questions, it is necessary to define the best biochemical, preferably non-invasive markers for the detection and monitoring of the disease.

The ideal marker would be the one that would make it easier to set up a diagnosis, help assess the severity of the disease, identify the phenotypes $A D$, and predict the individual response to the therapy. However, the ideal marker does not exist.

Moreover, laboratory assays currently used in practice are mainly focus on monitoring immune or inflammatory changes (e.g. total and specific $\mathrm{lgE}$, eosinophilic granulocyte counts, cytokine release assays) and less to control of skin-barrier function impairment including FLG deficiency. These are for example the determination of TWEL and $\mathrm{pH}$ of the skin $(73,74)$.

For the last few decades, scientists have been trying to establish methods for detection of FLG deficiency, its degradation products, or products of profilaggrin processing as well as other barrier proteins. The analytical samples include skin biopsy, animal skin biopsy samples, human skin equivalents and reconstructed skin samples, samples collected by tape stripping technique and serum (75-80). Non-invasive in vivo methods for investigation of skin components are implemented in clinical practice. Among novel methods, Raman spectroscopy, an optical biopsy method, offers the possibility for real-time characterization of skin components, including FLG (81). The concentration of the NMF ingredients, for example amino acids and their derivatives is determined using the HPLC method (76). Activities of enzymes involved in the processing of profilaggrin into FLG, and FLG paraffin-embeded samples are also determined, by the use of immunohistochemical staining $(82,83)$. In the studies there are also particularly important methods of genotyping of FLG, as well as proteomic analysis of FLG deficiency.

Of the non-invasive markers, it appears that significant potential for the clinical course of $A D$ and therapeutic effect has TSLP expression determination using tape-stripping approach to sampling and mass spectrometry as well as determination of serum TSLP concentration by enzyme-linked immunosorbent assay (ELISA) $(84,85)$. Also, thymus and activation-regulated chemokine (TARC), highaffinity ligand for CC-chemokine receptor 4 (CCR4) in serum or plasma of patients has been proposed as a marker of disease activity $(86,87)$.

A significant number of biomarkers include direct or indirect evaluation of FLG deficiency. However, taking into account the multifactorial nature of $A D$, it is necessary to define more clearly the most reliable biomarker for a single phenotype $A D$ (12). Accordingly, it will also be possible to apply appropriate therapy with the aim of repairing the skin barrier.

In addition to the appropriate preventive measures, effective therapeutic approach to maintain adequate skin barrier function and inflammatory control are also needed. Within primary non-pharmacological prevention, some authors advise avoiding various types of allergens, while some promote tolerance. Early sensitization in the first year of life, especially to food allergens, e.g. peanuts and milk, increases the risk for asthma to the third year of life of a children even 7-fold (88). Other authors state that sensitization to food allergens can develop before food is consumed, and that it occurs through inflammation of the skin (allergens can be found in home dust and creams and oils used for the treatment of new-born babies) (89). It is therefore considered that early oral consumption of such food can lead to tolerance, and that transcutaneous exposure to food allergens can lead to food sensitization. Based on the described causal link between early sensitization through damaged skin barrier and later development of atopic diseases such as asthma and AR, Johanson and Hershey promote immune tolerance as a "therapeutic" strategy or early introduction of "allergic" food (90). It has been described that the permeability of new-born skin is increased due to the insufficient presence of ceramide, which is associated with increased risk of later development of $A D$ (91). A review by Lowe et al. focused on skin as a goal for the prevention of atopic march includes the concept of preventive skin treatment with emollients from the first weeks of life to 6 or 8 months of age, i.e. prevention before the onset of symptoms of AD (92). Few well-designed larger tri- 
als are currently underway to demonstrate the long-term effects of moisturizing on the incidence of $A D$ and on the incidence of FA and allergic airways disease. The authors discuss the advantages and disadvantages of such a strategy, as well as the choice of emollients, and their safety and acceptability (92).

As a part of the primary therapeutic prevention of further $A D$ development, as well as prevention of progression in asthma and AR, methods for compensation of reduced FLG level or its degradation products (NMF) are also developed.

According to Irvine, the group of candidates for FLG replacement therapy would include patients with FLG mutations, patients with variation in FLG repeat numbers, intra-genetic copy number variation, patients with secondary reduced FLG (acquired deficiency), severe and persistent type of $A D$ that have allergic sensitization and in the future could develop asthma, and patients with genodermatoses (93). Currently, about 80 clinical trials focused on topical AD treatment are ongoing, including drugs that would have the ultimate effect on FLG increase (94). Animal and human investigations of drugs focused on mutant alleles, drugs increasing FLG expression by promotion of a healthy allele, direct FLG substitution drugs, hence recombinant FLG are currently underway (95). Other therapeutic measures are the renewal of extracellular skin lipid profiles (various emollients with a mixture of ceramides, cholesterol, and fatty acids), regeneration of $\mathrm{pH}$, and skin hydration. As immune dysregulation remains the key problem in $A D$ and shares pathophysiological features with other atopic disorders, it is very important to control inflammation. Various biological drugs such as dupilumab (monoclonal antibody directed against the IL-4 receptor a subunit that blocks signaling of both IL-4 and IL-13), nemolizumab (target IL-13), ustekinumab and lebrikizumab (targeting IL-31) are in research $(31,96,97)$. However, further investigations should be used to determine the timing of the initiation of preventive measures, the effectiveness of various forms of therapy, safety, and the mode of administration/dosage and the duration of the effect.

\section{Conclusion}

It is indisputable that the interactions between impaired epidermal barrier and dysregulation of the innate and adaptive immune system, in association with environmental risk factors, are involved in pathogenesis of AD. Atopic dermatitis is the most commonly occurring disease in an early life, which is associated with increased risk of asthma and AR. The scientific literature is dominated by works that $A D$ of hereditary or other origin are considered as an initiating event in the atopic march and the lack of FLG as a key component of the epidermal differentiation complex, as one of the first participants in pathogenesis of AD. In this context, if the skin barrier function is impaired, or if it is not repaired in the case of a pathogenic process already exists, it will be possible to provide a continuous allergen entrance, and the immune system will continuously produce antibodies. It is therefore expected that, along with various preventive measures recommended for maintaining the barrier function, therapeutic-oriented barrier restoration in this context of FLG replacement and $A D$ prevention will minimize the risk of allergic immunization as well as the development of asthma and AR. To monitor the effect of such therapy and the therapy that is in use, it is also necessary to find suitable laboratory markers. The complete pathogenesis of $A D$ and the pathway to explain atopic march, despite numerous new findings, including the significance of FLG deficiency, are still not quite clear due to their complexity and are in the focus of numerous researchers.

Accordingly, researchers should continue to work on the identification of molecular basis and environmental triggers of $A D$, on the association of the immune system with FLG deficiency, but also with other proteins of the epidermal differentiation complex. That will help to establish appropriate prevention and therapeutic algorithms to prevent or at least slow the atopic march.

\section{Potential conflict of interest}

None declared. 


\section{References}

1. Coca $A F$, Cooke RA. On the classification of the phenomena of hypersensitiveness. J Immunol. 1923;8:163-82.

2. Zheng T, Yu J, Oh MH, Zhu Z. The atopic march: progression from atopic dermatitis to allergic rhinitis and asthma. Allergy Asthma Immunol Res. 2011;3:67-73. https://doi. org/10.4168/aair.2011.3.2.67

3. Salazar-Espinoza JF. The atopic march. A Literature Review. Int J Med Students. 2014;2:119-24.

4. Licari A, Castagnoli R, Denicolò CF, Rossini L, Marseglia A, Marseglia GL. The nose and the lung: United airway disease? Front Pediatr. 2017;5:44-7. https://doi.org/10.3389/ fped.2017.00044

5. Spergel JM, Paller AS. Atopic dermatitis and the atopic march. J Allergy Clin Immunol. 2003;112:S118-27. https://doi. org/10.1016/j.jaci.2003.09.033

6. Czarnowicki T, Krueger JG, Guttman-Yassky E. Novel concepts of prevention and treatment of atopic dermatitis through barrier and immune manipulations with implications for the atopic march. J Allergy Clin Immunol. 2017;139:1723-34. https://doi.org/10.1016/j. jaci.2017.04.004

7. Barberio G, Pajno GB, Vita D, Caminiti L, Canonica GW, Passalacqua G. Does a "reverse" atopic march exist? Allergy. 2008;63:1630-2. https://doi.org/10.1111/j.13989995.2008.01710.x

8. Belgrave DCM, Simpson A, Buchan IE, Custovic A. Atopic dermatitis and respiratory allergy: What is the link. Curr Derm Rep. 2015;4:221-7. https://doi.org/10.1007/s13671015-0121-6

9. Dharmage SC, Lowe AJ, Matheson MC, Burgess JA, Allen KJ, Abramson MJ. Atopic dermatitis and the atopic march revisited. Allergy. 2014;69:17-27. https://doi.org/10.1111/ all. 12268

10. Ogrodowczyk A, Markiewicz L, Wroblewska B. Mutations in the filaggrin gene and food allergy. Prz Gastroenerol. 2014;9:200-7. https://doi.org/10.5114/pg.2014.45100

11. Hill DA, Spergel JM. The atopic march. Critical evidence and clinical relevance. Ann Allergy Asthma Immunol. 2018;120:131-7. https://doi.org/10.1016/j.anai.2017.10.037

12. Amat F, Soria A, Tallon P, Bourgoin-Heck M, Lambert N, Deschildre $A$, et al. New insights into the phenotypes of atopic dermatitis linked with allergies and asthma in children: An overview. Clin Exp Allergy. 2018;48:919-34. https://doi. org/10.1111/cea.13156

13. Hogan MB, Peele K, Wilson NW. Skin barrier function and its importance at the start of the atopic march. J Allergy (Cairo). 2012;2012:901940. https://doi.org/10.1155/2012/901940

14. Egawa G, Weninger W. Pathogenesis of atopic dermatitis: $A$ short review. Cogent Biology. 2015;1:1-10. https://doi.org/1 0.1080/23312025.2015.1103459

15. Han H, Roan F, Ziegler SF. The atopic march: current insights into skin barrier dysfunction and epithelial cell-derived cytokines. Immunol Rev. 2017;278:116-30. https://doi. org/10.1111/imr.12546

16. Gillespie RM, Brown SJ. From the outside-in: Epidermal targeting as a paradigm for atopic disease therapy. World
J Dermatol. 2015;4:16-32. https://doi.org/10.5314/wjd. v4.i1.16

17. Ito T, Liu YJ, Arima K. Cellular and molecular mechanisms of TSLP function in human allergic disorders - TSLP programs the "Th2 code" in dendritic cells. Allergol Int. 2012;61:35-43. https://doi.org/10.2332/allergolint.11-RAl-0376

18. Li M. Current evidence of epidermal barrier dysfunction and tymic stromal lymphopoietin in the atopic march. Eur Res Rev. 2014;23:292-8. https://doi. org/10.1183/09059180.00004314

19. Wallmeyer L, Dietert K, Sochorova M, Gruber AD, Klauser B, Vavrova K, Hedtrich S. TSLP is a direct trigger for T cell migration in filaggrin-deficient skin equivalents. Scientific Reports. 2017;7:774. https://doi.org/10.1038/s41598-01700670-2

20. Kim JH, Bae HC, Ko NY, Lee SH, Jeong SH, Lee H, et al. Thymic stromal lymphopoietin downregulates filaggrin expression by signal transducer and activator of transcription 3 (STAT3) and extracellular signal-regulated kinase (ERK) phosphorylation in keratinocytes. J Allergy Clin Immunol. 2015;136:205208.e9. https://doi.org/10.1016/j.jaci.2015.04.026

21. Khan SJ, Dharmage SC, Matheson MC, Gurrin LC. Is the atopic march related to confounding by genetics and early-life environment? A systemic review of sibship and twin data. Allergy. 2018;73:17-28. https://doi.org/10.1111/all.13228

22. Steinert PM, Canieri JS, Teller DC, Landsale-Eceles JD, Dale $B A$. Characterisation of a class of cationic proteins that specifically interact with intermediate filaments. Proc Natl Acad Sci. 1981;78:4097-101. https://doi.org/10.1073/ pnas.78.7.4097

23. Jang SI, Steinert PM. Activator protein-1 activity is involved in the regulation of the cell-type specific expresion from the proximal promoter of human profilaggrin gene. J Biol Chem. 1996;271:24105-14. https://doi.org/10.1074/ jbc.271.39.24105

24. Kam E, Resing KA, Lim SK, Dale BA. Identification of rat epidermal profilaggrin phosphatase as a member of the protein phosphatase 2A family. J Cell Sci. 1993;106:219-26.

25. Sandilands $A$, Sutherland $C$, Irvine $A D, M c$ Lean WH. Filaggrin in the frontline: Role in skin barrier function and disease. J Cell Sci. 2009;122:1285-94. https://doi.org/10.1242/ jcs.033969

26. Čepelak I, Dodig S, Filipović-Grčić J. Filaggrin - multifunctional protein. Acta Med Croatica. 2016;70:125-30.

27. Brown SJ, Mc Lean WH. One remarkable molecule: Filaggrin. J Invest Dermatol. 2012;132:751-62. https://doi. org/10.1038/jid.2011.393

28. Meng L, Wang L, Tang H, Tang X, Jiang X, Zhao J, et al. Filaggrin Gene Mutation c.332 delA is associated with various clinical features of atopic dermatitis in the Chinese han population. PloS ONE. 2014;9:e98235. https://doi.org/10.1371/ journal.pone.0098235

29. Brown SJ, Asai Y, Cordell HJ, Campbell LE, Zhao Y, Liao H, et al. Loss-of-function variants in the filaggrin gene are a significant risk factor for peanut allergy. J Allergy Clin Immunol. 2011;127:661-7. https://doi.org/10.1016/j.jaci.2011.01.031 
30. Talasila S, Paller AS, eds. Filaggrin and Non-cutaneous Disease. In: Thyssen JP, Maibach HI, eds. Filaggrin. Basic science, epidemiology, clinical aspects and management. Heidelberg, New York, Dordrecht, London: Springer; 2014. p. 31159.

31. Carlsen $B C$, ed. Therapeutics and other interventions. In: Thysen JP, Maibach HI eds. Filaggrin. Basic science, epidemiology, clinical aspects and management. Heidelberg, New York, Dordrecht, London: Springer; 2014. p. 359-73.

32. Nutten S. Atopic Dermatitis: Global epidemiology and risk factors. Ann Nutr Metab. 2015;66(supp/1):8-16. https://doi. org/10.1159/000370220

33. Spergel JM. From atopic dermatitis to asthma: the atopic march. Ann Allergy Asthma Immunol. 2010;105:99-106. https://doi.org/10.1016/j.anai.2009.10.002

34. Valdman-Grinshpoun Y, Ben-Amital, Zvulunov A. Barrier-restoring therapies in atopic dermatitis: Current approaches and future perspectives. Dermatol Res Pract. 2012;2012:923134. https://doi.org/10.1155/2012/923134

35. Rerknimitr P, Otsuka A, Nakashima C, Kabashima. The etiopathogenesis of atopic dermatitis: barrier disruption, immunological derangement, and pruritus. Inflamm Regen. 2017;37:14-5. https://doi.org/10.1186/s41232-017-0044-7

36. Schmid-Grendelmeier $P$, Simon $D$, Simon $H U$, Akidis $C A$, Wüthrich B. Epidemiology, clinical features, and immunology of the "intrinsic" (non-IgE-mediated) type of atopic dermatitis (constitutional dermatitis). Allergy. 2001;56:841-9. https://doi.org/10.1034/j.1398-9995.2001.00144.x

37. Brunner PM, Silverberg Jl, Guttman-Yassky E, Paller AS, Kabashima K, Amagai K, et al. Increasing comorbidities suggest that atopic dermatitis is a systemic disorder. J Invest Dermatol. 2017;137:18-25. https://doi.org/10.1016/j. jid.2016.08.022

38. Smith FJ, Irvine AD, Terron-Kwiatkowski A, Sandilands $A$, Campbell $L E$, Zhao $Y$, et al. Loss-of-function mutations in gene encoding filaggrin cause is ichthyosis vulgaris. Nat $\mathrm{Ge}$ net. 2006;38:337-42. https://doi.org/10.1038/ng1743

39. Thyssen JP, Kezić S. Causes of epidermal filaggrin reduction and their role in the pathogenesis of atopic dermatitis. J Allergy Clin Immunol 2014;134:792-9. https://doi. org/10.1016/j.jaci.2014.06.014

40. Ahn $K$. The role of air pollutants in atopic dermatitis. J Allergy Clin Immunol. 2014;134:993-9. https://doi. org/10.1016/j.jaci.2014.09.023

41. Wang IJ, Karmaus WJ. The effect of phthalate exposure and filaggrin gene variants on atopic dermatitis. Environ Res. 2015;136:213-8. https://doi.org/10.1016/j.envres.2014.09.032

42. Pendaries V, Le Lamer M, Cau L, Hansmann B, Malaisse J, Kezić $S$, et al. In a three-dimensional reconstructed human epidermis filaggrin-2 is essential for proper cornification. Cell Death Disease. 2015;6:e1656. https://doi.org/10.1038/ cddis.2015.29

43. Margolis DJ, Gupta J, Apter AJ, Ganguly T, Hoffstad O, Papadopoulos $M$, et al. Filaggrin-2 variation is associated with more persistent atopic dermatitis in African American subjects. J Allergy Clin Immunol. 2014;133:784-9. https://doi. org/10.1016/j.jaci.2013.09.015
44. Moffatt MF. SPINK5: a gene for atopic dermatitis and asthma. Clin Exp Allergy. 2004;34:325-7. https://doi. org/10.1111/j.1365-2222.2004.01915.x

45. Guttman-Yassky E, Suárez-Fariñas M, Chiricozzi A, Nograles $K E$, Shemer A, Fuentes-Duculan J, et al. Broad defects in epidermal cornification in atopic dermatitis identified through genomic analysis. J Allergy Clin Immunol. 2009;124:123544.e58. https://doi.org/10.1016/j.jaci.2009.09.031

46. Barnes KC. An update on genetics of atopic dermatitis: scratching the surface in 2009. J Allergy Clin Immunol. 2010;125:16-29.e1.https://doi.org/10.1016/j.jaci.2009.11.008

47. Samuelov L, Sarig O, Harmon RM, Rapaport D, Ishida-Yamamoto $A$, Isakov $O$, et al. Desmoglein 1 deficiency results in severe dermatitis, multiple allergies and metabolic wasting. Nat Genet. 2013;45:1244-8. https://doi.org/10.1038/ ng.2739

48. Bin L, Leung DYM. Genetic and epigenetic studies of atopic dermatitis. Allergy Asthma Clin Immunol. 2016;12:52. https://doi.org/10.1186/s13223-016-0158-5

49. Darlenski R, Kazandjieva J, Hristakieva E, Fluhr JW. Atopic dermatitis as a systemic disease. Clin Dermatol. 2014;32:409-13. https://doi.org/10.1016/j.clindermatol.2013.11.007

50. Upton E, Schellack N, Motswaledi MH. A review of the risk factors and clinical presentation of childhood atopic eczema at the primary healthcare level. Curr Allergy Clin Immunol. 2016;29:24-9.

51. De Benedetto A, Qualia CM, Baroody FM, Beck LA. Filaggrin expression in oral, nasal, and esophageal mucosa. J Invest Dermatol. 2008;128:1594-7. https://doi.org/10.1038/ sj.jid.5701208

52. Cubero JL, Isidoro-Garcia M, Segura N, Pescador DB, Sanz $C$, Lorente $F$, et al. Filaggrin gene mutations and new SNP in asthmatic patients: a cross-sectional study in Spanish population. Allergy Asthma Clin Immunol. 2016;12:31. https:// doi.org/10.1186/s13223-016-0137-x

53. Oyoshi MK, Murphy GF, Geha RS. Filaggrin-deficient mice exhibit Th17-dominated skin inflammation and permissiveness to epicutaneous sensitization with protein antigen. J Allergy Clin Immunol. 2009;124:485-93. https://doi. org/10.1016/j.jaci.2009.05.042

54. Irvine $A D$, McLean $W H$, Leung DY. Filaggrin mutations associated with skin and allergic diseases. N Engl J Med. 2011;365:1315-27. https://doi.org/10.1056/NEJMra1011040

55. Dodig S, ed. [Astma.] Zagreb: Medicinska naklada; 1991. (in Croatian)

56. Moore WC, Meyers DA, Wenzel SE, Teague WG, Li H, Li X, et al. National Heart, Lung, and Blood Institute's Severe Asthma Research Program. Identification of asthma phenotypes using cluster analysis in the Severe Asthma Research Program. Am J Respir Crit Care Med. 2010;181:315-23. https:// doi.org/10.1164/rccm.200906-08960C

57. Holt PG, Strickland DH. Interactions between innate and adaptive immunity in asthma pathogenesis: new perspectives from studies on acute exacerbations. J Allergy Clin Immunol. 2010;125:963-72. https://doi.org/10.1016/j. jaci.2010.02.011 
58. Holgate ST, Davies DE, Rorke S, Cakebread J, Murphy G, Powell RM, et al. ADAM 33 and its association with airway remodeling and hyperresponsiveness in asthma. Clin Rev Allergy Immunol. 2004;27:23-34. https://doi.org/10.1385/ CRIAl:27:1:023

59. Deykin A, Massaro AF, Drazen JM, Israel E. Exhaled nitric oxide as a diagnostic test for asthma: online versus offline techniques and effect of flow rate. Am J Respir Crit Care Med. 2002;165:1597-601. https://doi.org/10.1164/rccm.2201081

60. Palmer CN, Irvine AD, Terron-Kwiatkowski A, Zhao Y, Liao $H$, Lee SP, et al. Common loss-of function variants of epidermal barrier protein filaggrin are a major predisposing factor for atopic dermatitis. Nat Genet. 2006;38:441-6. https://doi. org/10.1038/ng1767

61. Heimall J, Spergel JM. Filaggrin mutations and atopy: consequences for future therapeutics. Expert Rev Clin Immunol. 2012;8:189-97. https://doi.org/10.1586/eci.11.100

62. Osawa $R$, Akiyama $M$, Shimizu $H$. Filaggrin gene defects and the risk of developing allergic disorders. Allergol Int. 2011;60:1-9. https://doi.org/10.2332/allergolint.10RAI-0270

63. Thomsen AF, ed. Asthma. In: Thyssen JP, Maibach HI eds. Filaggrin. Basic Science, Epidemiology, Clinical Aspects and Management. Heidelberg, New York, Dordrecht, London: Springer; 2014. p.169-81.

64. Marenholz I, Nickel R, Rüschendorf F, Schulz F, Esparza-Gordillo J, Kerscher $T$, et al. Filaggrin loss-of-function mutations predispose to phenotypes involved in the atopic march. J Allergy Clin Immunol. 2006;118:866-71. https://doi. org/10.1016/j.jaci.2006.07.026

65. Bønnelykke K, Pipper CB, Tavendale R, Palmer CN, Bisgaard $H$. Filaggrin gene variants and atopic diseases in early childhood assessed longitudinally from birth. Pediatr Allergy Immunol. 2010;21:954-61. https://doi.org/10.1111/j.13993038.2010.01073.x

66. Bousquet J, van Cauwenbredge P, Khaltaev N. Allergic rhinitis and its impact on asthma. J Allergy Clin Immunol. 2001;108(Suppl):S147-S334. https://doi.org/10.1067/ mai.2001.118891

67. Naclerio RM. Allergic rhinitis. N Engl J Med 1991;325:860-9.

68. Pawankar R, MoriS, Ozu C, Kimura S. Overview on the pathomechanisms of allergic rhinitis. Asia Pac Allergy. 2011;1:15767. https://doi.org/10.5415/apallergy.2011.1.3.157

69. Togias A. Rhinitis and asthma: evidence for respiratory system integration. J Allergy Clin Immunol. 2003;111:117183. https://doi.org/10.1067/mai.2003.1592

70. Chawes BL. Upper and lower airway pathology in young children with allergic-and non-allergic rhinitis. Dan Med Bull. 2011;58:B4278.

71. Weidinger S, O'Sullivan M, Illig T, Baurecht H, Depner M,

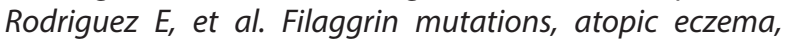
hay fever, and asthma in children. J Allergy Clin Immunol. 2008;121:1203-9.e1.https://doi.org/10.1016/j.jaci.2008.02.014

72. Ziyab AH, Karamus W, Zhang H, Holloway JW, Steck SE, Ewart $S$, et al. Association of filaggrin variants with asthma and rhinitis: is eczema or allergic sensitization status an effect modifier? Int Arch Allergy Immunol. 2014;164:308-18. https://doi.org/10.1159/000365990
73. Kelleher M, Dunn-Galvin A, Hourihane JO, Murray D, Campbell $L E$, McLean $W H$, et al. Skin barrier dysfunction measured by transepidermal water loss at 2 days and 2 months predates and predicts atopic dermatitis at 1 year. J Allergy Clin Immunol. 2015;135:930-5.e1. https://doi. org/10.1016/j.jaci.2014.12.013

74. Nagashima T, Komeda T, Yamamoto SI, Yajima T, Kemuriyama T. Measurement of skin surface $\mathrm{pH}$ with a non-invasive Dry $\mathrm{pH}$ Sensor. 5th International Conference on Biomedical Engineering and Technology (ICBET 2015). 2015;81:1-5.

75. Eberlein-König B, Schaefer T, Huss-Marp J, Darsow $U$, Moe Hrenschlager $M$, Herbert $O$, et al. Skin surface $\mathrm{pH}$, stratum corneum hydration, trans-epidermal water loss and skin roughness related to atopic eczema and skin dryness in a population of primary school children. Acta Derm Venereol. 2000;80:188-91. https://doi. org/10.1080/000155500750042943

76. Đapić I, Jakasa I, Yau NLH, Kezić S, Kammeyer A. Evaluation of an HPLC method for the determination of natural moisturizing factors in the human stratum corneum. Analytical letters. 2013;46:2133-44. https://doi.org/10.1080/00032719 .2013 .789881

77. Kawasaki H, Nagao K, Kubo A, Hata T, Shimizu A, Mizuno $H$, et al. Altered stratum corneum barrier and enhanced percutaneous immune responses in fi laggrin-null mice. J Allergy Clin Immunol. 2012;129:1538-46.e6. https://doi. org/10.1016/j.jaci.2012.01.068

78. Hönzke S, Wallmeyer L, Ostrowski A, Radbruch $M$, Mundhenk L, Schäfer-Korting $M$, et al. Influence of Th2 cytokines on the cornified envelope, tight junction proteins, and B-defensins in filaggrin-deficient skin equivalents. J Invest Dermatol. 2016;136:631-9. https://doi.org/10.1016/j. jid.2015.11.007

79. Wallmeyer L, Lehnen D, Eger N, Sochorová M, Opálka $L$, Kováčik $A$, et al. Stimulation of PPARa normalizes the skin lipid ratio and improves the skin barrier of normal and filaggrin deficient reconstructed skin. J Dermatol Sci. 2015;80:102-10. https://doi.org/10.1016/j.jdermsci.2015.09.012

80. Riethmuller C, McAleer MA, Koppes SA, Abdayem R, Franz $J$, Haftek $M$, et al. Filaggrin breakdown products determine corneocyte conformation in patients with atopic dermatitis. J Allergy Clin Immunol. 2015;136:1573-80.e2. https:// doi.org/10.1016/j.jaci.2015.04.042

81. Darlenski R, Sassning S, Tsankov N, Fluhr JW. Non-invasive in vivo methods for investigation of the skin barrier physical properties. Eur J Pharm Biopharm. 2009;72:295-303. https://doi.org/10.1016/j.ejpb.2008.11.013

82. McAleer MA, Jakasa I, Raj N, O'Donnell CPF, Lane ME, Rawlings $A V$, et al. Early-life regional and temporal variation in filaggrin derived natural moisturizing factor, filaggrinprocessing enzyme activity, corneocyte phenotypes and plasmin activity: implications for atopic dermatitis. Br J Dermatol. 2018;179:431-41. https://doi.org/10.1111/bjd.16691

83. Howell MD Kim BE, Gao P, Grant AV, Boguniewicz M, DeBenedetto $A$, et al. Cytokine modulation of atopic dermatitis filaggrin skin expression. J Allergy Clin Immunol. 2007;120:150-5. https://doi.org/10.1016/j.jaci.2007.04.031 
84. González FJ, Alda J, Moreno-Cruz B, Martínez-Escanamé $M$, Ramírez-Elías MG, Torres-Álvarez B, et al. Use of Raman spectroscopy in the early detection of filaggrin-related atopic dermatitis. Skin Res Technol. 2011;17:45-50. https://doi. org/10.1111/j.1600-0846.2010.00461.x

85. Kim J, Kim BE, Lee J, Han Y, Jun HY, Kim H, et al. Epidermal thymic stromal lymphopoietin predicts the development of atopic dermatitis during infancy. J Allergy Clin Immunol. 2016;137:1282-85.e4. https://doi.org/10.1016/j. jaci.2015.12.1306

86. Lee EB, Kim KW, Hong JY, Jee HM, Sohn MH, Kim KE. Increased serum thymic stromal lymphopoietin in children with atopic dermatitis. Pediatr Allergy Immunol. 2010;21:e45760. https://doi.org/10.1111/j.1399-3038.2009.00919.x

87. Gu CY, Gu L, Dou X. Serum levels of thymus and activation-regulated chemokine can be used in the clinical evaluation of atopic dermatitis. Int J Dermatol. 2015;54:e261-5. https://doi.org/10.1111/ijd.12830

88. Tran MM, Lefebvre DL, Dharma C, Dai D, Lou WYW, Subbarao $P$, et al. Predicting the atopic march: Results from the Canadian Healthy Infant Longitudinal Development Study. J Allergy Clin Immunol. 2018;141:601-7.e8. https://doi. org/10.1016/j.jaci.2017.08.024

89. Tran MM. Can the atopic march be predicted? Ann Allergy Asthma Immunol. 2018;120:115-6. https://doi. org/10.1016/j.anai.2017.12.016

90. Johansson E, Hershey GK. An impaired epithelial barrier contributes to the atopic march. Ann Allergy Asthma Immunol. 2018;120:118-9. https://doi.org/10.1016/j.anai.2017.11.008
91. Hoeger PH, Schreiner V, Klaassen IA, Enzmann CC, Friedrichs $K$, Bleck $O$. Epidermal barrier lipids in human vernix caseosa: corresponding ceramide pattern in vernix and fetal skin. Br J Dermatol. 2002;146:194-201. https://doi.org/10.1046/ j.1365-2133.2002.04584.x

92. Lowe AJ, Leung AYM, Tang MLK, Su JC, Allen KJ. The skin as a target for prevention of the atopic march. Ann Allergy Asthma Immunol 2018;120:145-51. https://doi.org/10.1016/j. anai.2017.11.023

93. Irvine $A D$. Crossing barriers; Restoring Barriers? Filaggrin Protein Replacement Takes a Bow. J Invest Dermatol. 2014;134:313-4. https://doi.org/10.1038/jid.2013.506

94. Yaldman-Grinshpoun $Y$, Ben-Amital D, Zvulunov A. Barrier-restoring therapies in atopic dermatitis: Current approaches and future perspectives. Dermatol Res Practice. 2012;2012:923134. https://doi.org/10.1155/2012/923134

95. Stout TE, McFarland T, Mitchell JC, Appukuttan B J, Stout T. Recombinant filaggrin is internalized and processed to correct filaggrin deficiency. J Invest Dermatol. 2014;134:423-9. https://doi.org/10.1038/jid.2013.284

96. Otsuka A, Doi H, Egawa G, Maekawa A, Fujita T, Nakamizo $S$, et al. Possible new therapeutic strategy to regulate atopic dermatitis through upregulating filaggrin expression. J Allergy Clin Immunol. 2014;133:139-46.e1. https://doi. org/10.1016/j.jaci.2013.07.027

97. Boguniewicz M. Biologic therapy for atopic dermatitis: Moving beyond the practice parameter and guidelines. $J$ Allergy Clin Immunol Pract. 2017;5:1477-87. https://doi. org/10.1016/j.jaip.2017.08.031 